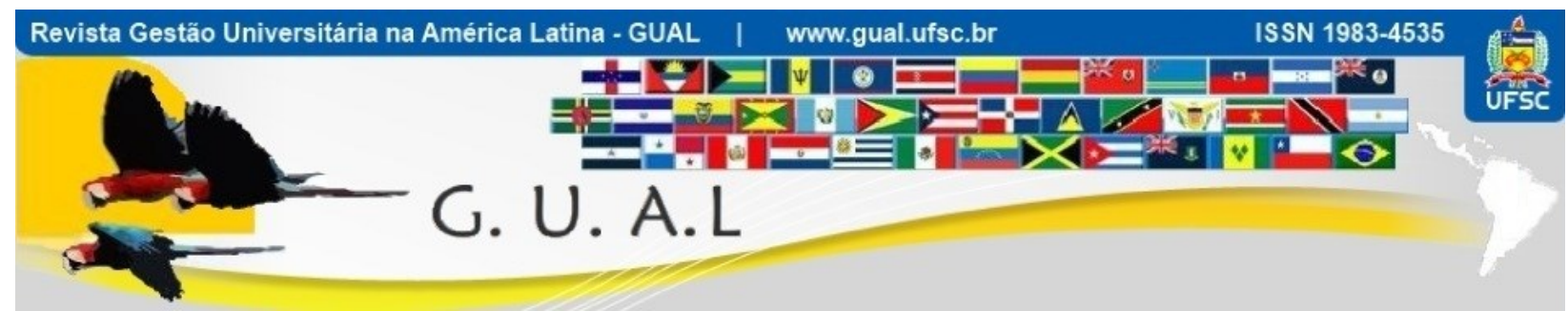

DOI: http://dx.doi.org/10.5007/1983-4535.2019v12n3p1

\title{
LIDERANÇA E GESTÃO DO CONHECIMENTO: DESAFIOS ORGANIZACIONAIS DA PÓS-GRADUAÇÃO E PESQUISA EM UMA UNIVERSIDADE FEDERAL BRASILEIRA
}

\author{
LEADERSHIP AND KNOWLEDGE MANAGEMENT: ORGANIZATIONAL \\ CHALLENGES OF THE GRADUATE AND RESEARCH IN A BRAZILIAN \\ FEDERAL UNIVERSITY
}

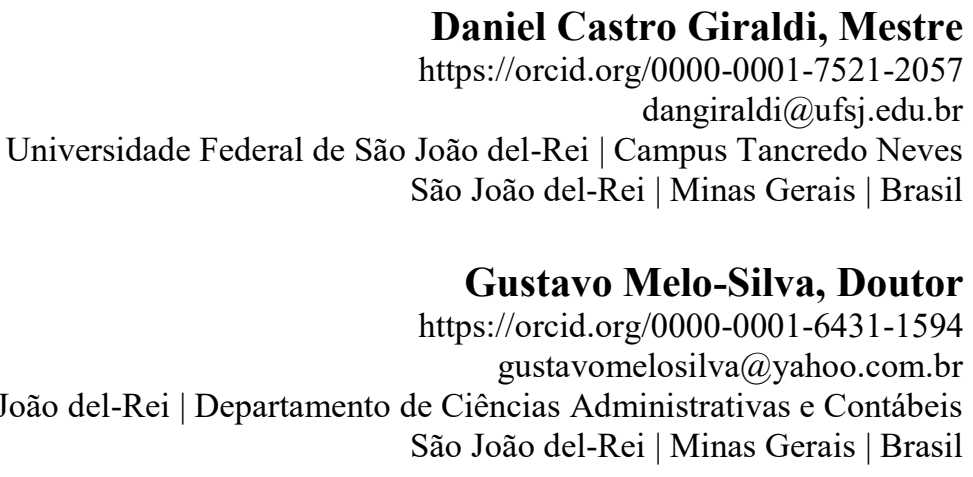

Universidade Federal de São João del-Rei | Departamento de Ciências Administrativas e Contábeis

Recebido em 01/junho/2018

Aprovado em 26/março/2019

Publicado em 02/setembro/2019

Sistema de Avaliação: Double Blind Review

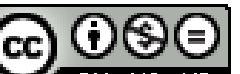

Esta obra está sob uma Licença Creative Commons Atribuição-Uso. 


\begin{abstract}
RESUMO
Este artigo apresenta um estudo de caso de caráter hermenêutico e aplicado, realizado com o objetivo de compreender quais são os principais desafios vivenciados pelos gestores da PróReitoria de Pesquisa e Pós-Graduação da Universidade Federal de São João del-Rei (PROPE/UFSJ) em seus esforços de consolidação dos programas de pós-graduação stricto sensu. Os resultados mostraram que os principais desafios são a ausência de ações voltadas à qualificação funcional de docentes para o exercício do cargo de coordenador de programas de mestrado e de doutorado e a falta de apoio empresarial regional à pesquisa desenvolvida nesses programas. Os dados colhidos sugerem que a prática da liderança no âmbito da unidade organizacional estudada vem sendo impulsionada mais em razão de problemas e dúvidas por parte dos gestores do que em razão de planejamentos e estratégias, o que indica que esses profissionais tem atualmente um perfil gerencial mais reativo do que proativo.
\end{abstract}

Palavras-chave: Instituições de Educação Superior. Desafios da Pós-Graduação e Pesquisa. Liderança Universitária.

\begin{abstract}
This paper presents a hermeneutic and applied case study carried out to understand the main challenges experienced by administrators of the Pro-Rectory of Graduate Studies and Research of the Federal University of São João del-Rei (UFSJ), in their efforts to consolidate master and doctoral programs. The results showed that main challenges are the absence of actions aimed at the functional qualification of professor holding the position of coordinator of master and doctoral programs, and the lack of regional business support to the research developed in these programs. The data collected suggest that practice of leadership within the organizational unit studied has been driven more by uncertainties and perplexities on the part of these managers than by plans and strategies, which indicates these professionals currently have a more reactive rather than proactive managerial profile.
\end{abstract}

Keywords: Higher Education Institutions. Challenges of Graduate and Research. University Leadership. 


\section{INTRODUÇÃO}

Os principais desafios da gestão universitária na atualidade podem ser atribuídos à crescente tensão entre colegialismo ${ }^{1}$ e gerencialismo como modelos de governança nessas organizações (BLASCHKE; FROSTE; HATTKE, 2014; BRADSHAW; FREDETTE, 2009) e aos recentes fenômenos da massificação do acesso à educação superior e do empreendedorismo universitário, em especial no âmbito da pós-graduação (BERNHEIM, CHAUÍ, 2008; MIDDLEHURST, 2001; YOKOYAMA, 2006).

Nesta esfera, é crescente a pressão para que as Instituições de Educação Superior (IES) se tornem o que a literatura (ETZKOWITZ, 2004; GUERRERO; CUNNINGHAM; URBANO, 2015) denomina de "universidades empreendedoras", pela qual se exige cada vez mais a essas instituições o estabelecimento de parcerias com governos e empresas, assegurando que haja uma efetiva transferência de conhecimentos e de tecnologias produzidos na academia à sociedade e, assim, uma contribuição direta ao desenvolvimento econômico e social.

Esse fomento ao empreendedorismo por governos e empresas vem incentivando cada vez mais a competitividade acadêmica, tanto a que se dá entre os pesquisadores individualmente, como a que ocorre entre universidades e entre sistemas nacionais de educação superior, na expectativa de que essa disputa acadêmica de várias dimensões resulte no maior número possível de parcerias entre universidades, empresas e governos e, a partir disso, em pesquisas com maior potencial de impacto na vida econômica e política das nações (IPIRANGA; FREITAS; PAIVA, 2010; YOKOYAMA, 2006).

A competitividade acadêmica tem como lastro um florescente gerencialismo nas organizações universitárias (TINOCO, 2013). A literatura (DOUGHERTY, 2016; HICKS, 2012) registra que a incorporação cada vez maior de sistemas de financiamento à pesquisa baseados em desempenho (performance-based research funding systems) acrescenta evidências à constatação de que há em processo um movimento internacional de aprofundamento da competitividade acadêmica entre pessoas, organizações universitárias e países.

\footnotetext{
${ }^{1}$ A literatura no campo da gestão universitária (BRADSHAW; FREDETTE, 2009; MIDDLEHURST; GOREHAM; WOODFIELD, 2009) registra que nas universidades ao redor do mundo prevalece historicamente um modelo de governança "colegiada", pelo qual os processos decisórios são conduzidos em conjunto por atores com peso decisório equivalente e nos quais múltiplas demandas e interesses diversos tem de ser trazidos à deliberação coletiva.
} 
Em sintonia com desafios observados internacionalmente na gestão universitária contemporânea, existem também aqueles particulares a cada IES e que emergem a partir de demandas locais singulares. No caso da UFSJ, um dos principais objetivos que essa organização universitária tem no presente é a consolidação de seus programas de pósgraduação stricto sensu (UFSJ, 2014).

A seguir, mostramos como a literatura vem discutindo questões relacionadas historicamente às lógicas institucionais (BLASCHKE; FROSTE; HATTKE, 2014) embutidas na estrutura organizacional e às práticas de liderança presentes em organizações universitárias públicas e privadas. Em seguida, descrevemos os procedimentos metodológicos empregados. $\mathrm{Na}$ seção seguinte, analisamos e discutimos os dados coletados. Por último, são feitas considerações nas quais os achados do estudo são resumidos, algumas limitações apontadas e sugestões de pesquisas futuras apresentadas.

\section{ORGANIZAÇÃO UNIVERSITÁRIA: COLEGIALISMO E DEPARTAMENTALISMO}

Segundo Macfarlane (2016), organizações colegiadas podem ser caracterizadas como aquelas nas quais seu funcionamento é pautado no consenso como critério legitimador das tomadas de decisão, no compartilhamento de poder e na responsabilização coletiva. Nessas organizações, as diferenças de status entre os colaboradores são atenuadas na cultura organizacional e, por isso, eles interagem relativamente enquanto iguais, dividindo aspirações e compromissos comuns.

Segundo Macfarlane $(2007,2016)$, tais padrões contribuem para o exercício da chamada "cidadania acadêmica" (academic citizenship), por ele definida como o conjunto de tarefas, responsabilidades e virtudes acadêmicas de docentes e pesquisadores que existem para além das atividades de ensino e de pesquisa, como por exemplo as ações de avaliação de produtos acadêmicos de colegas de trabalho (peer reviews), a participação em bancas examinadoras, a orientação de estudantes, etc., as quais refletem obrigações comuns de profissionais acadêmicos mundo afora junto à comunidade que os cercam, as quais contribuem, decisivamente, para a construção e manutenção da infraestrutura da vida acadêmica.

No cenário educacional de nível superior brasileiro, uma característica essencial das organizações universitárias públicas administradas pelo governo federal e que constitui uma de suas lógicas institucionais é a chamada "departamentalização" que formata a estrutura 


\section{LIDERANÇA E GESTÃO DO CONHECIMENTO: DESAFIOS ORGANIZACIONAIS DA PÓS- GRADUAÇÃO E PESQUISA EM UMA UNIVERSIDADE FEDERAL BRASILEIRA \\ DOI: http://dx.doi.org/10.5007/1983-4535.2019v12n3p1}

organizacional da maior parte das IFES desde a reforma universitária de 1968 (MACEDO et al., 2005), ditando o modo pelo qual as distintas funções universitárias são organizadas e como o trabalho administrativo e acadêmico é conduzido.

Desde sua legalização enquanto estrutura organizacional universitária no Brasil, a departamentalização vem fomentando uma literatura de discussão a respeito de sua adequação enquanto instrumento para alcance de propósitos tradicional e historicamente fundamentais das universidades, tais como a liberdade acadêmica e a busca pela unidade dos saberes (GRACIANI, 1982).

Segundo Fávero (2006), o departamento universitário brasileiro vem se constituindo historicamente num espaço de alocação burocrático-administrativa de professores e contribuindo para inibir o trabalho coletivo de produção de conhecimento, concorrendo para que o foco macro institucional da universidade possa ser ignorado em prol da busca por satisfação de demandas setoriais específicas de natureza departamental (BORGES; ARAÚJO, 2001).

\section{GERENCIALISMO E GESTÃO DO CONHECIMENTO NAS ORGANIZAÇÕES UNIVERSITÁRIAS}

O crescimento observado aproximadamente nos últimos vinte anos no número de estudos sobre como funciona a gestão praticada nas IES mundo afora foi grandemente estimulado por reformas neoliberais implementadas ao longo das últimas quatro décadas em países de todos os continentes (MIDDLEHURST, 2001).

Essas reformas, cuja característica essencial tem sido a instilação de estilos empresariais de gestão e de liderança (business-like leadership styles) advindos do mundo corporativo na governança das universidades, vem gerando desde então um problema tanto prático, para os profissionais que administram essas organizações, quanto teórico, para aqueles que se dedicam à pesquisa no campo da gestão universitária.

Dado que nas universidades impera histórica e tradicionalmente uma colegialidade em seus processos decisórios, a literatura (BLASCHKE; FROSTE; HATTKE, 2014) aponta que a institucionalização do ideário do business-like ou da administração tipicamente empresarial nas universidades coloca aos gestores dessas organizações o desafio de coadunar princípios de 


\section{LIDERANÇA E GESTÃO DO CONHECIMENTO: DESAFIOS ORGANIZACIONAIS DA PÓS- GRADUAÇÃO E PESQUISA EM UMA UNIVERSIDADE FEDERAL BRASILEIRA \\ DOI: http://dx.doi.org/10.5007/1983-4535.2019v12n3p1}

governança aparentemente opostos, colegialismo de um lado e gerencialismo e liderismo ${ }^{2}$ de outro.

No contexto brasileiro, segundo Luiz Carlos Bresser-Pereira, responsável pela introdução oficial de reformas gerencialistas no país enquanto ministro de Estado durante o primeiro governo federal de FHC (1995-1998), a reformulação gerencialista do sistema de educação superior nacional não ocorreu, ao menos não enquanto fruto de uma ação política intencional por parte do governo federal (LEITE, 2014). Não obstante essa afirmação do mais importante policy maker do gerencialismo público brasileiro, a literatura (SGUISSARDI, 2006; TOURINHO; PALHA, 2014) registra que a influência concreta da Nova Gestão Pública (New Public Management) se fez e se faz notar na IES do país, visto que desde 1997 as IFES vem tendo os produtos de seus programas de mestrado e de doutorado avaliados regularmente pelo Ministério da Educação (MEC), via Coordenação de Aperfeiçoamento de Pessoal de Nível Superior (CAPES).

Por meio dessa avaliação, que hoje no âmbito do sistema superior de educação brasileiro possui caráter quadrienal ${ }^{3}$, índices de produtividade e critérios de comparabilidade (benchmarking) e de ranquemento entre essas instituições foram estabelecidos e consolidados, garantindo assim condições necessárias para a medição do desempenho dessas organizações universitárias e, também, para fundamentar a responsabilização (accountability) de seus gestores, em grande medida induzida no Brasil pela influência político-administrativa da Nova Gestão Pública e por sua preconização da adoção de instrumentos de avaliação, auditoria, acreditação e físcalização tipicamente empregados por organizações empresariais.

Uma ferramenta gerencialista que vem sendo cada vez mais estudada no âmbito da gestão universitária é a chamada "Gestão do Conhecimento" (GC), largamente ressaltada na literatura (FULLWOOD; ROWLEY; DELBRIDGE, 2013; RAMACHANDRAN; WONG; CHONG, 2013) como instrumento de gestão com aptidão para aprimorar a integração entre trabalho administrativo e acadêmico dentro das IES, bem como para aumentar a integração entre pesquisadores atuantes em centros de pesquisa e no setor industrial.

Sunalai e Beyerlein (2015) afirmam que a literatura em GC no âmbito das IES mostra

\footnotetext{
2 Segundo Ekman et al. (2018), liderismo diz respeito a quaisquer ações organizacionais voltadas para o desenvolvimento de agentes de mudança organizacional com capacidade para definir agendas e soluções, unificar interesses divergentes, atender às necessidades dos cidadãos e gerar entusiasmo e compartilhamento de valores em uma IES.

3 http://www.capes.gov.br/sala-de-imprensa/noticias/8456-quadrienal-2017-apresenta-mudancas-na-avaliacaoda-pos-graduacao. Acesso em 18 de abril de 2018.
} 


\section{LIDERANÇA E GESTÃO DO CONHECIMENTO: DESAFIOS ORGANIZACIONAIS DA PÓS- GRADUAÇÃO E PESQUISA EM UMA UNIVERSIDADE FEDERAL BRASILEIRA \\ DOI: http://dx.doi.org/10.5007/1983-4535.2019v12n3p1}

que a implementação de iniciativas formais em GC concorre diretamente para aprimorar a colaboração em atividades de pesquisa, para aumentar o número de projetos de pesquisa em uma universidade, para melhorar a comunicação entre pesquisadores e, assim, para facilitar o surgimento de novas ideias relativas ao desenvolvimento de pesquisas futuras.

Segundo Dalkir (2005), uma definição adequada para a chamada "Gestão do Conhecimento" é aquela que a entende como

\footnotetext{
a coordenação deliberada e sistemática das pessoas, tecnologias e processos de uma organização, a fim de agregar valor através da reutilização e da inovação. Esta coordenação é alcançada por meio da criação, partilha e aplicação de conhecimentos, bem como através da inserção das melhores práticas e das lições valiosas apreendidas pela organização (DALKIR, 2005, p. 3).
}

No que diz respeito ao tema da coordenação e sincronização especificamente do trabalho desenvolvido nas IES, a literatura (FULLWOOD; ROWLEY; DELBRIDGE, 2013; RAMACHANDRAN; WONG; CHONG; 2013) observa que, para assegurar a sustentabilidade da colaboração efetiva entre colaboradores, cabe a uma organização a promoção de práticas e de situações que os aproximem cotidianamente e, dessa maneira, propiciem a construção de confiança e de respeito mútuos e o compartilhamento de informações e de conhecimentos relevantes para a organização.

\section{LIDERISMO NAS ORGANIZAÇÕES UNIVERSITÁRIAS}

A literatura (BERGAMINI, 1994; NORTHOUSE, 2013) mostra que a liderança é um fenômeno relevante nas Ciências Administrativas por estar envolvida intimamente em todos os processos de mudança organizacional, sempre presente em processos de tomada de decisão, em definições de estratégias, nas comunicações entre colaboradores, na delegação e na avocação de responsabilidades organizacionais, etc.

A diferenciação entre os conceitos de "gestor" e de "líder" é objeto de discussões frequentes na literatura. Segundo Kotter (1990 apud NORTHOUSE, 2013), as funções da gestão são bastante diferentes das funções da liderança: enquanto a função primordial da primeira é reduzir o caos nas organizações produzindo ordem e consistência em suas dinâmicas, a função da liderança é especificamente a de produzir mudanças organizacionais através do estabelecimento de novos objetivos e direcionamentos à organização e a de alinhar esforços, na condição de uma força-motriz para assegurar a ocorrência dessas mudanças. 


\section{LIDERANÇA E GESTÃO DO CONHECIMENTO: DESAFIOS ORGANIZACIONAIS DA PÓS- GRADUAÇÃO E PESQUISA EM UMA UNIVERSIDADE FEDERAL BRASILEIRA \\ DOI: http://dx.doi.org/10.5007/1983-4535.2019v12n3p1}

Em particular em organizações baseadas e intensivas em conhecimento tais como as organizações universitárias, em que este é tanto o seu principal ativo como também o seu principal input e output, o exercício da liderança se coloca como um desafio bastante complexo, já que a produção de conhecimentos (via pesquisa), a transmissão de conhecimentos (via ensino) e serviços sociais baseados neste conhecimento (via extensão) constitui a missão fundamental desse tipo de organização, sendo o administrador universitário, por conseguinte, um gestor de ativos, insumos e resultados peculiares (MIDDLEHURST; GOREHAM; WOODFIELD, 2009).

Esse desafio ganha uma dificuldade adicional em virtude da tradicional horizontalização hierárquica que conforma o padrão típico de relacionamento entre os acadêmicos (ADRIANO; RAMOS, 2015; BLASCHKE; FROSTE; HATTKE, 2014), a qual faz com que professores e pesquisadores, do ponto de vista funcional, sejam comumente teorizados como constituindo uma espécie de "comunidade" (CLARK, 1986), sendo esta a razão pela qual vários autores (ANDRADE; RAMOS, 2015) caracterizam a figura do Reitor muito mais como a de um "primeiro entre iguais" (primus inter pares).

Resultado da elevada liberdade e autonomia que os profissionais acadêmicos possuem no exercício de suas funções nas universidades, essa horizontalidade hierárquica faz com que o fenômeno da liderança em ambientes universitários não seja uma propriedade organizacional apriorística, dada ex ante, visto não existir no relacionamento funcional dos profissionais da academia ${ }^{4}$ o desempenho de papéis fixos ou estáveis de líder e de liderado, ao contrário do que ocorre nas organizações empresariais em geral (BRADSHAW; FREDETTE, 2009).

No contexto universitário, além de relacionamentos institucionais horizontais predominam também estruturas decisórias que apresentam essa mesma qualidade, sob a forma dos diversos conselhos consultivos e deliberativos (BLASCHKE; FROSTE; HATTKE, 2014; BRADSHAW; FREDETTE, 2009), as quais, em conjunto com a departamentalização, concorrem para restringir oportunidades de protagonismo individual, bem como para distribuir o exercício da liderança por dentre as múltiplas unidades administrivo-acadêmicas (JONES et al., 2012, 2014), uma situação que torna bastante complexa nas IES as relações entre liderança, governança e gestão no dia-a-dia dessas organizações (BLASCHKE;

\footnotetext{
${ }^{4}$ Por oposição aos profissionais "administrativos" que atuam nessas organizações (tais como os técnicos administrativos e os técnicos de laboratório, os quais desenvolvem o que pode ser chamado de "atividades universitárias-meio").
} 


\section{LIDERANÇA E GESTÃO DO CONHECIMENTO: DESAFIOS ORGANIZACIONAIS DA PÓS- GRADUAÇÃO E PESQUISA EM UMA UNIVERSIDADE FEDERAL BRASILEIRA \\ DOI: http://dx.doi.org/10.5007/1983-4535.2019v12n3p1}

FROSTE; HATTKE, 2014).

De acordo com Orzano et al. (2008), a abertura a novas ideias e perspectiva organizacionais, a consciência plena acerca de como o trabalho de um colaborador afeta o de outros dentro da organização e a onipresença de uma comunicação precisa, oportuna e capaz de acomodar conflitos e simplificar feedbacks são iniciativas que atuam como fatores viabilizadores de GC e podem ser sintetizadas todas elas sob um denominador comum: a liderança organizacional.

\section{PROCEDIMENTOS METODOLÓGICOS}

Com base em uma pesquisa documental que fundamentou a elaboração dos roteiros de entrevista empregados para guiar a obtenção de informações sobre as experiências gerenciais dos gestores dos programas de pós-graduação stricto sensu da UFSJ, em como acerca de suas crenças, valores e expectativas em relação aos desafios de consolidação desses programas na IES estudada, bem como a partir do quadro conceitual-teórico delineado na última seção, desenvolvemos um estudo de caso único, de tipo exploratório, de cariz qualitativo, com enfoque a um só tempo hermenêutico e aplicado, com fulcro na seguinte pergunta de pesquisa, a qual encerra um duplo questionamento diretamente relacionado à abordagem dada ao estudo: Quais são os principais desafios enfrentados pelos gestores da UFSJ nos esforços de consolidação dos programas de pós-graduação stricto sensu desta IFES e como a Gestão do Conhecimento pode contribuir neste enfrentamento?

Quanto à amostragem aplicada a este estudo, foi empregado o chamado "método não-probabilístico de amostragem por julgamento" (COUTINHO, 2013), em que a seleção dos elementos da população componente de uma amostra depende diretamente do julgamento intencional do pesquisador e cuja validade e consistência se funda na justificabilidade dessa seleção em relação aos objetivos explicitamente traçados para uma pesquisa (FONTANELLA; RICAS; TURATO, 2008).

Foram entrevistados todos os gestores administrativos vinculados diretamente à Divisão de Projetos e Qualificação da PROPE/UFSJ. Quanto aos gestores acadêmicos, foram entrevistados 16 de um total de 27 Coordenadores de programas de pós-graduação stricto sensu. O encerramento da coleta de dados primários junto ao grupo de gestores acadêmicos ocorreu na qualidade de "fechamento amostral por saturação teórica" (FONTANELLA; RICAS; TURATO, 2008). Em certo momento do processo, as informações de interesse para 
os propósitos da pesquisa se tornaram redundantes, já que as narrativas coletadas foram constituindo ao longo do processo um núcleo comum de sentidos ou significados fundamentais (percepções, ideias, expectativas, crenças, valores, opiniões) que os gestores estudados atribuem aos fenômenos de gestão da PROPE/UFSJ, os quais bastaram para o alcance dos objetivos específicos da pesquisa e, assim, induziram à decisão de decretação do término da coleta.

\section{RESULTADOS E DISCUSSÃO}

Esta seção apresenta os principais temas identificados no conjunto das entrevistas realizadas por meio da técnica de interpretação de dados denominada "análise temática de conteúdo". Para ilustrá-los, foram incluídos trechos de relatos dos entrevistados, os quais foram codificados numericamente conforme a ordem temporal de realização das entrevistas.

As narrativas colhidas sugerem que os docentes da UFSJ, quando ingressam na função de Coordenador de programas de pós-graduação stricto sensu, experimentam de modo geral um grande sentimento de dúvida sobre como administrar uma unidade organizacional voltada tanto para a especialização de recursos humanos, os mestrandos e doutorandos, como para a produção de conhecimentos científicos e tecnológicos.

Vários relatos coletados mostram que os Coordenadores, mesmo aqueles que já passaram por mais de uma experiência de avaliação do programa pela CAPES, órgão responsável por acompanhar e mensurar o desempenho desses programas no país, possuem ainda muitas dúvidas em relação às atribuições próprias do cargo de Coordenador de um programa de mestrado e de doutorado, principalmente a respeito a como utilizar de maneira adequada o sistema informacional pelo qual os programas fazem sua prestação de contas, a chamada "Plataforma Sucupira".

Os excertos de relato abaixo, que abordam questões relativas à produção de dados e informações sobre os programas pelos gestores acadêmicos, ilustram como isso parece refletir entre eles um sentimento geral de dúvida sobre como gerir uma tarefa de suma importância no exercício do dever de responsabilização (accountability) colocado a esses gestores pela CAPES, mesmo entre aqueles com experiência na função:

[...] Não somente eu, mas os colegas daqui mesmo, nas reuniões, falam sobre dúvidas relativas ao preenchimento da Plataforma Sucupira. É uma coisa que gera dúvidas que a gente tem que resolver sozinho, por tentativa e erro. E isso é complicado, porque a gente está sujeito a erros que podem até 
comprometer a avaliação do curso, então a gente fica apreensivo, para fazer o que realmente precisa ser feito, para que o curso seja bem avaliado e responda às demandas da CAPES [E 06].

[...] Houve uma reunião patrocinada pela PROPE alguns dias atrás e algumas das questões, em termos de dúvida que eu tinha, pude ver que não necessariamente isso tem a ver com inexperiência, como a minha, mas tem a ver também com o grande dinamismo da área da pós-graduação, com a grande quantidade de modificações de normas e com as políticas novas que vão surgindo e que vão se entremeando, se misturando, e isso causava dúvida na cabeça de algumas pessoas e pelos discursos delas se percebia que eram pessoas muito sagazes, muito experientes, mas que mesmo assim eram pegas em certos enredamentos burocráticos, porque é tudo muito entrelaçado [E 10].

Este último excerto se harmoniza com justificativas teóricas comumente encontradas na literatura sobre GC a respeito da pertinência da formalização de iniciativas em GC no âmbito de órgãos e entidades da Administração Pública. Por exemplo, Samiotis et al. (2014) procuram justificar essa pertinência mencionando uma série de propriedades organizacionais características das organizações públicas: o fato de que este tipo de organização depende, para funcionar, de uma série de leis, normas, regulamentos e decisões judiciais; o fato de que essas organizações precisam processar uma enorme quantidade de dados e informações advindas de diferentes fontes documentais governamentais; o fato de que a aplicação e a interpretação das leis de um país é uma tarefa não-trivial e ambígua para os administradores públicos em geral, de modo que uma atualização constante de conhecimentos por parte desses gestores para lidar com tais circunstâncias político-administrativas constitui uma condição de eficácia para qualquer tipo de organização da Administração Pública nacional, aí incluídas as organizações universitárias (SUNALAI; BEYERLEIN, 2015).

Ramachandran et al. (2013) ressaltam que a presença de uma estratégia de implementação de iniciativas em GC na visão administrativa da cúpula gestora das universidades parece contribuir substantivamente para reforçar a disposição dos profissionais acadêmicos em colaborarem e compartilharem ideias a respeito de suas atividades e responsabilidades comuns. Este tipo de iniciativa é essencial para garantir as condições necessárias para uma interatividade permanente entre gestores administrativos e acadêmicos, a qual concorrerá para reduzir e, em algum momento na progressão deste processo, para anular o estado de dúvida, perplexidade e, em certos momentos, de paralisia gerencial que, segundo os relatos, acomete muitos dos gestores acadêmicos da UFSJ no dia-a-dia da gestão de seus programas de pós-graduação stricto sensu. 


\section{LIDERANÇA E GESTÃO DO CONHECIMENTO: DESAFIOS ORGANIZACIONAIS DA PÓS- GRADUAÇÃO E PESQUISA EM UMA UNIVERSIDADE FEDERAL BRASILEIRA \\ DOI: http://dx.doi.org/10.5007/1983-4535.2019v12n3p1}

Além da ausência de iniciativas formais de capacitação dos gestores acadêmicos do universo da pós-graduação stricto sensu da UFSJ, relatos de alguns entrevistados permitem inferir que não há, em alguns casos, uma comunicação interna suficiente dentro das Coordenadorias, dentre os próprios colegas de departamento ou de programa, de modo que a ausência de uma atenção gerencial mais cuidadosa com os processos de transição entre Coordenadores, dados o caráter rotativo do cargo e a brevidade de seu exercício, vem resultando, ainda de acordo com o ponto de vista dos entrevistados, em prejuízo administrativo-acadêmico aos programas de pós-graduação da UFSJ. O excerto de relato abaixo ilustra essa percepção, que também é geral entre os Coordenadores:

[...] Eu tive uma certa dificuldade quando eu assumi a Coordenação e quando eu assumi a Vice-Coordenação, pois tanto eu como minha colega que assumiu a Coordenação na época tivemos dificuldade de ter acesso a situações ou processos que estavam em andamento pelo antigo de Coordenador. Então esse processo de transição, se as pessoas não são próximas, é muito complicado, porque a pessoa que entra ela fica bem perdida em relação àquilo que está acontecendo naquele momento no programa [E 14].

A literatura em gestão universitária (BATISTA, 2006; CRANFIELD; TAYLOR, 2008; MIDDLEHURST, 2001) mostra que o perfil geral dos gestores das universidades é o de um profissional altamente capacitado, com formação em áreas de conhecimento diversas. Entretanto, tais profissionais iniciam sua atuação em funções universitárias administrativas sem necessariamente já possuírem conhecimentos gerenciais, quando então passam a adquirir tais conhecimentos empiricamente e de maneira caótica ou, em outras palavras, de maneira não-estruturada. Assim, de forma recorrente no cotidiano desses gestores, a busca efetiva para determinar o rumo e a direção dos programas, bem como para estabelecer mudanças na maneira como os programas são conduzidos, parece ser uma disposição que emerge sempre situacionalmente (BOLDEN; PETROV; GOSLING, 2009), a partir de dificuldades que surgem "de repente", ao invés de pautadas em planejamentos e estratégias que estabeleçam previamente um curso de ação gerencial claro e racional aos Coordenadores dos programas de mestrado e de doutorado da UFSJ.

Das entrevistas, infere-se ainda que a teoria que atribui à prática da liderança em ambientes organizacionais educacionais um caráter "distribuído" (BOLDEN; PETROV; GOSLING, 2009) se mostra aplicável às relações administrativas presentes no caso estudado, a PROPE/UFSJ, haja vista a grande autonomia que os gestores acadêmicos entrevistados 


\section{LIDERANÇA E GESTÃO DO CONHECIMENTO: DESAFIOS ORGANIZACIONAIS DA PÓS- GRADUAÇÃO E PESQUISA EM UMA UNIVERSIDADE FEDERAL BRASILEIRA \\ DOI: http://dx.doi.org/10.5007/1983-4535.2019v12n3p1}

acreditam ter na gestão acadêmica dos programas de pós-graduação stricto sensu dessa IFES.

Essa grande autonomia de gestão acadêmica parece indicar que as condições organizacionais que tipicamente estruturam a gestão universitária da maioria das IFES no Brasil, em específico o departamentalismo das unidades acadêmicas e o colegialismo dos processos decisórios acadêmicos, contribuem para reforçar o que poderíamos chamar de "distributivismo" do fenômeno da liderança organizacional dentro da PROPE e de suas unidades vinculadas.

A liderança praticada na PROPE/UFSJ parece ser caracterizada inclusive pelo que poderíamos chamar de uma "distribuição por problemas", dado que o exercício da liderança parece surgir nas interações gerenciais existentes na PROPE fundamentalmente a partir de situações administrativas caóticas vivenciadas no dia-a-dia das Coordenadorias.

Os relatos indicam, por conseguinte, não haver na relação entre os gestores administrativos e acadêmicos da PROPE um protagonismo de atuação por parte de um único indivíduo ou mesmo de um grupo específico deles. Os relatos sugerem que parece existir uma ampla diversidade de interesses distintos em jogo em cada programa de mestrado e de doutorado, cada um deles atribuindo um peso específico a determinadas dimensões da atuação dos programas, tais como a produção intelectual de docentes e discentes, a inserção social dos programas, etc.

A questão da tensão subjetiva entre colegialismo e gerencialismo na direção das organizações universitárias, amplamente abordada e discutida na literatura em gestão universitária (ADRIANO; RAMOS, 2015), parece não fazer muito sentido para se compreender as relações entre os gestores administrativos e acadêmicos que atuam na pósgraduação e pesquisa da UFSJ, já que restrições a práticas gerencialistas não foram manifestadas ao longo das entrevistas.

Algumas situações relatadas mostram que há, na esfera da intenção e expectativa, um anseio concreto por outras ações gerenciais típicas do setor empresarial (ou seja, por práticas "gerencialistas"), tendo sido colhidas evidências neste sentido através da coleta de dados secundários. Pudemos constatar, por exemplo, que está atualmente em construção no website da PROPE um FAQ (Frequently Asked Questions) destinado a disseminar conhecimentos administrativo-acadêmicos à comunidade interna e externa à UFSJ, o qual, em si mesmo, se constitui enquanto uma típica ferramenta de $\mathrm{GC}$, evidenciando que já há nesta unidade organizacional uma disposição para a GC. 
Em razão disso, propomos nos dois parágrafos que se seguem algumas ferramentas de GC cuja aplicação pode contribuir para diminuir o estado generalizado de dúvida e perplexidade gerencial que atravessa cotidianamente o estado de espírito desses gestores e para inverter a lógica reativa de exercício da liderança que predomina em suas práticas (em direção a uma lógica pró-ativa) e, consequentemente, para promover as capacidades de liderança desses gestores.

Ações de "coaching" (uma típica ferramenta de GC) pela PROPE, por parte de seus gestores acadêmicos, podem conferir utilidade organizacional ao know-how detido pelos gestores administrativos e serem empregadas para, sempre que necessário, aconselhar gestores acadêmico seja de programas novos, seja de programas antigos, contribuindo para o compartilhamento de conhecimentos gerenciais tácitos que podem ser decisivos para o aprimoramento da capacidade de gestão de programas de pós-graduação stricto sensu por parte dos Coordenadores.

Outra ferramenta de GC que pode ser empregada para este mesmo fim é o "storytelling", 6 a qual atua na conversão de conhecimentos tácitos em conhecimentos explícitos (DALKIR, 2005), um meio pelo qual gestores de programas de pós-graduação stricto sensu experientes podem compartilhar conhecimentos administrativo-acadêmicos ${ }^{7}$, de uma só vez, a vários gestores novatos ou iniciantes no cargo de Coordenador desses programas, contribuindo para reduzir dúvidas, perplexidades e problemas no cotidiano dos Coordenadores desses programas.

Entretanto, não apenas questões organizacionais vem os desafiando, adversidades político-econômicas também tem colocado barreiras ao desenvolvimento dos programas e ao alcance de suas metas e objetivos de consolidação, particularmente no que se refere à inserção social deles:

\footnotetext{
5 Segundo Dalkir (2005), o chamado "coaching" diz respeito a uma atividade de GC na qual um coach (treinador) não participa diretamente da execução de quaisquer atividades organizacionais, mas orienta, apoia, dialoga e acompanha pessoas no desempenho de funções, com base nas diretrizes estratégicas de uma organização.

6 Segundo Dalkir (2005), o chamado "storytelling" é uma narrativa organizacional em que relatos de experiências pessoais vivenciadas por colaboradores que já atuaram em determinadas atividades, tarefas ou processos de interesse da organização são transmitidas a outros membros da organização.

Ao longo deste artigo, empregamos a expressão "conhecimento administrativo-acadêmico" para designar todo e qualquer conhecimento referente a atividades e processos comumente desenvolvidos no âmbito de programas de pós-graduação stricto sensu das IFES.
} 
[...] A gente tem um problema muito sério no Brasil, das empresas no Brasil, que é exatamente o fato de elas não acreditarem na pesquisa feita na academia. A Petrobrás tem essa cultura, ela tem seu centro de pesquisas no Rio de Janeiro. Então, quando você demonstra conhecimento e domínio, ela tranquilamente se dispõe a colaborar e fazer parcerias com você. Outros professores do programa que já procuraram outras empresas para parcerias tiveram o pequeno dissabor de as empresas não acreditarem, de não estarem dispostas a colaborar, nem com manutenção de equipamentos, nem com bolsas. O máximo que a gente tem conseguido com parcerias junto a empresas é doação de material de consumo. Mas conseguir comprar equipamento e financiar bolsas, isso é algo que a gente ainda não conseguiu efetivar com a iniciativa privada [E 4].

[...] Muito se acreditou na EMBRAPA, mas a EMBRAPA, como parceiro nosso aqui, no meu caso aqui não contribuiu em nada. Mesmo na área de cereais, eu não vejo contribuição. Eles mais ganham do que doam. Eles tem orientandos nossos que trabalham em programas deles, então eles estão lucrando com isso. A EMBRAPA não financia nada aqui [E 15].

Os relatos acima permitem inferir que a experiência de alguns gestores de programas diretamente relacionados à pesquisa de tecnologias evidencia que uma condição necessária para a possibilidade de empreendedorismo universitário (ETZKOWITZ, 2004), a saber, a valorização dos processos de construção ou criação de conhecimento científico, de conhecimento tecnológico e de inovação, ainda não são uma realidade na cultura organizacional das empresas que atuam no entorno aos campi da UFSJ. Ou seja, parece que o interesse dessas empresas em arranjos colaborativos está voltado unicamente para resultados, não havendo disponibilidade empresarial para participar do processo que produz tais resultados.

Em específico no que diz respeito ao fomento a uma cultura de apoio empresarial à pesquisa, os gestores desses programas poderiam implementar ferramentas de GC voltadas para dinamizar o compartilhamento de conhecimentos administrativoacadêmicos entre eles acerca de experiências já vivenciadas de tentativas de estabelecimento de tratativas voltadas para colaborações com empresas localizadas no entorno da UFSJ, tais como, por exemplo, as ferramentas denominadas "storytelling" e "análise pós-ação", bem como ferramentas para o compartilhamento de conhecimentos econômicos, administrativos e políticos com líderes empresariais da região, como por exemplo a ferramenta

\footnotetext{
${ }^{8}$ Segundo Almeida (2016), a chamada "análise pós-ação" é uma reunião entre colaboradores com o propósito de debater e analisar alguma experiência organizacional para a detecção de falhas a serem evitadas em experiências futuras similares.
} 
"brainstorming"9. Esta última poderia ser aplicada durante a realização de eventos em que líderes empresariais regionais seriam convidados para compartilhar crenças e expectativas em relação à colaboração com a universidade visando ao desenvolvimento comum e é uma ação que contribuiria também, paralelamente, para aprofundar a inserção social dos programas, contribuindo diretamente para a consolidação da qualidade e do bom desempenho deles.

\section{CONSIDERAÇÕES FINAIS}

O objetivo geral deste estudo de caso foi compreender quais são os principais desafios dos gestores da pós-graduação e pesquisa da UFSJ nas ações de consolidação dos programas de pós-graduação desta IFES para, a partir disso, propor iniciativas formais em GC que podem contribuir para auxiliar esses gestores a lidarem de maneira mais hábil com tais desafios.

As descobertas do estudo de caso aqui relatado mostraram também que os gestores da PROPE, em particular os gestores acadêmicos (isto é, os Coordenadores de programas de mestrado e de doutorado), possuem muitas inquietações e dificuldades a respeito de como lidar adequadamente com os desafios por eles identificados no que se refere à gestão dos programas.

Em linha com o que se pode constatar em teorizações disponíveis na literatura internacional em gestão universitária (JONES et al., 2012, 2014), os resultados sugerem ainda que a capacidade de liderança dos gestores administrativos e dos gestores acadêmicos que atuam na PROPE pode ser inclusive desenvolvida e aprimorada a partir do envolvimento e participação desses profissionais em iniciativas de GC.

Quanto às limitações das contribuições empírico-teóricas trazidas por este estudo, com base nas dimensões de viabilizadores constantes dos frameworks sobre GC (BATISTA, 2006; HEISIG, 2009), podemos afirmar que uma insuficiência notória dele é a sua não-abordagem da chamada "dimensão tecnológica" identificada nesses quadros teóricos, já que deliberadamente optamos por explorar somente as dimensões "organizacionais", "culturais" e "pessoais" dos fatores que essa literatura reputa como viabilizadores de iniciativas bem sucedidas em GC.

Dessa maneira, sugere-se como domínio para a realização de pesquisas futuras estudos

\footnotetext{
${ }^{9}$ Segundo Dalkir (2005), um “brainstorming” é uma reunião com o propósito de fomentar insights e a geração livre de ideias novas ou incomuns até então na cultura de uma organização.
} 
voltados para a compreensão das condições tecnológicas necessárias para assegurar, viabilizar e facilitar iniciativas de gestão de dados e informações em ambientes universitários brasileiros em geral e na UFSJ em particular, haja vista os recorrentes relatos quanto à dificuldade de gestão de dados e informações relacionadas ao funcionamento dos programas de pósgraduação stricto sensu desta instituição.

Ainda dentro do paradigma ao qual se filia este estudo de caso, sugere-se o desenvolvimento de estudos reflexivos ou interpretacionistas que discutam, com base em evidências, a pertinência de narrativas que apresentam o gerencialismo como um vilão na administração da vida acadêmica, as quais são comuns na literatura nacional (RIBEIRO; LEDA, 2016), não obstante ser possível constatar a presença também de estudos na direção contrária (FALQUETO; FARIAS, 2013).

Iniciativas desse tipo ainda concorrerão, naturalmente, para também aumentar o foco gerencial em processos primários de gestão universitária (TEELKEN, 2011) e para aumentar o conhecimento acadêmico sobre o desenvolvimento de capacidades de liderança (leadership capabilities) e de empreendedorismo universitário (university entrepreneurship) entre os gestores das IES, algo vital para o bom desempenho de uma organização da qual se espera uma cada vez maior articulação com empresas, governos e a sociedade em geral (GUERRERO; CUNNINGHAM; URBANO, 2015; GIBB; HANNON, 2006; YOKOYAMA, 2006).

\section{REFERÊNCIAS}

ADRIANO, B. M.; RAMOS, F. Liderança universitária: uma revisão das publicações nacionais e estrangeiras sobre o tema. Navus-Revista de Gestão e Tecnologia, v. 5, n. 4, p. 4664, 2015.

ALMEIDA, A. et al. Inovação e Gestão do Conhecimento. Rio de Janeiro: Editora FVG, 2016.

BATISTA, F. F. O desafio da gestão do conhecimento nas áreas de administração e planejamento das Instituições Federais de Ensino Superior (IFES). Repositório IPEA, 2006.

BERGAMINI, C. W. Liderança: a administração do sentido. Revista de Administração de Empresas, v. 34, n. 3, p. 102-114, 1994.

BERNHEIM, C. T.; CHAUÍ, M. de S. Desafios da universidade na sociedade do conhecimento. Unesco, 2008. 
BLASCHKE, S.; FROST, J.; HATTKE, F. Towards a micro foundation of leadership, governance, and management in universities. Higher education, v. 68, n. 5, p. 711-732, 2014.

BOLDEN, R.; PETROV, G.; GOSLING, J. Distributed leadership in higher education: What does it accomplish?. Leadership, v. 5, n. 3, p. 299-310, 2009.

BRADSHAW, P.; FREDETTE, C. Academic governance of universities: Reflections of a senate chair on moving from theory to practice and back. Journal of Management Inquiry, $\mathrm{v}$. 18, n. 2, p. 123-133, 2009.

CLARK, B. The higher education system: Academic organization in cross-national perspective. Univ of California Press, 1986.

COUTINHO, C. P. Metodologia de Investigação em Ciências Sociais e Humanas: teoria e prática. Edições Almedina, 2013.

CRANFIELD, D. J.; TAYLOR, J. Knowledge management and higher education: A UK case study. Electronic Journal of Knowledge Management, v. 6, n. 2, 2008.

DALKIR, K. Knowledge management in theory and practice. Elsevier, 2005.

DOUGHERTY, K. et al. Performance funding for higher education. JHU Press, 2016.

EKMAN, M.; LINDGREN, M.; PACKENDORFF, J. Universities need leadership, academics need management: discursive tensions and voids in the deregulation of Swedish higher education legislation. Higher Education, v. 75, n. 2, p. 299-321, 2018.

ETZKOWITZ, H. The evolution of the entrepreneurial university. International Journal of Technology and Globalisation, v. 1, n. 1, p. 64-77, 2004.

FALQUETO, J. M. Z.; FARIAS, J. S. A trajetória e a funcionalidade da universidade pública brasileira. Revista Gestão Universitária na América Latina-GUAL, v. 6, n. 1, 2013.

FÁVERO, M. de L. de A. A Universidade no Brasil: das origens à Reforma Universitária de 1968. Educar em Revista, n. 28, p. 17-36, 2006.

FONTANELLA, B. J. B.; RICAS, J.; TURATO, E. R. Amostragem por saturação em pesquisas qualitativas em saúde: contribuições teóricas. Cadernos de saúde pública, v. 24, p. 17-27, 2008.

FULLWOOD, R.; ROWLEY, J.; DELBRIDGE, R. Knowledge sharing amongst academics in UK universities. Journal of Knowledge Management, v. 17, n. 1, p. 123-136, 2013.

GRACIANI, Maria Stela Santos. O ensino superior no Brasil. Petrópolis: Vozes, 1982.

GUERRERO, M.; CUNNINGHAM, J.; URBANO, D.. Economic impact of entrepreneurial universities' activities: An exploratory study of the United Kingdom. 
Research Policy, v. 44, n. 3, p. 748-764, 2015.

HEISIG, P. Harmonisation of knowledege management - comparing $160 \mathrm{KM}$ frameworks around the globe. Journal of Knowledge Management, v. 13, n. 4, p. 4-31, 2009.

HICKS, D. Performance-based university research funding systems. Research policy, v. 41, n. 2, p. 251-261, 2012.

IPIRANGA, A. S. R.; FREITAS, A. A. F. de; PAIVA, T. A. O empreendedorismo acadêmico no contexto da interação universidade-empresa-governo. Cadernos EBAPE. BR, v. 8, n. 4, 2010.

JONES, S. et al. Distributed leadership: A collaborative framework for academics, executives and professionals in higher education. Journal of Higher Education Policy and Management, v. 34, n. 1, p. 67-78, 2012.

JONES, S. et al. Synthesising theory and practice: Distributed leadership in higher education. Educational Management Administration \& Leadership, v. 42, n. 5, p. 603-619, 2014.

LEITE, L. Q. Entrevista: reflexões de um reformador contemporâneo do Estado brasileiro: entrevista com Luiz Carlos Bresser Pereira, por Leonardo Queiroz Leite. Revista de Administração Pública, v. 48, n. 4, p. 1051-1070, 2014.

MACEDO, A. R. de et al. Educação superior no século XXI e a reforma universitária brasileira. Ensaio: avaliação e políticas públicas em educação, v. 13, n. 47, 2005.

MACFARLANE, B. Defining and rewarding academic citizenship: The implications for university promotions policy. Journal of Higher Education Policy and Management, v. 29, n. 3, p. 261-273, 2007.

MACFARLANE, B. Collegiality and performativity in a competitive academic culture. Higher Education Review, v. 48, n. 2, 2016.

MIDDLEHURST, R. University challenges: Borderless higher education, today and tomorrow. Kluwer Academic Publishers. 2001.

MIDDLEHURST, R.; GOREHAM, H.; WOODFIELD, S. Why research leadership in higher education? Exploring contributions from the UK's leadership foundation for higher education. Leadership, v. 5, n. 3, p. 311-329, 2009.

NORTHOUSE, P. G. Leadership: Theory and practice. Sage publications, 2013.

ORZANO, J. et al. A knowledge management model: implications for enhancing quality in health care. Journal of the American Society for Information Science and Technology, v. 59, n. 3, p. 489-505, 2008.

RAMACHANDRAN, S. D.; CHONG, S. C.; WONG, K. Y. Knowledge management 
practices and enablers in public universities: A gap analysis. Campus-Wide Information Systems, v. 30, n. 2, p. 76-94, 2013.

RIBEIRO, C. V. dos S.; LEDA, D. B. O trabalho docente no enfrentamento do gerencialismo nas universidades brasileiras: repercussões na subjetividade. Educação em Revista, v. 32, n. 4, 2016.

SAMIOTIS, K.; STOJANOVIC, N.; NTIOUDIS, S. Knowledge Management for Public Administrations: Technical Realizations of an Enterprise Attention Management System. Electronic Journal of Knowledge Management, v. 12, n. 3, p. 195-205, 2014.

SGUISSARDI, V. Reforma universitária no Brasil-1995-2006: precária trajetória e incerto futuro. Educação \& Sociedade, v. 27, n. 96, p. 1021-1056, 2006.

SUNALAI, S.; BEYERLEIN, M. Exploring knowledge management in higher education institutions: Processes, influences, and outcomes. Academy of Educational Leadership Journal, v. 19, n. 3, p. 289, 2015.

TEELKEN, C. Compliance or pragmatism: How do academics deal with managerialism in higher education? A comparative study in three countries. Studies in Higher Education, v. 37, n. 3, p. 271-290, 2012.

TINOCO, D. dos S. A influência do novo gerencialismo público na política de educação superior. Interface, v. 10, n. 2, 2013.

TOURINHO, M. M.; PALHA, M. das D. C. A Capes, a universidade e a alienação gestada na pós-graduação. Cadernos EBAPE. BR, v. 12, n. 2, 2014.

UNIVERSIDADE FEDERAL DE SÃO JOÃO DEL-REI (UFSJ). Plano de Desenvolvimento Institucional. 2014. Disponível em: http://www.ufsj.edu.br/portal2repositorio/File/pplan/PDI\%20VERSAO\%202014.pdf. Acesso em: 05 de fevereiro de 2017.

YOKOYAMA, K. Entrepreneurialism in Japanese and UK universities: Governance, management, leadership, and funding. Higher Education, v. 52, n. 3, p. 523-555, 2006. 